\title{
Attention capture by contour onsets and offsets: No special role for onsets
}

\author{
DERRICK G. WATSON and GLYN W. HUMPHREYS \\ University of Birmingham, Edgbaston, Birmingham, England
}

\begin{abstract}
In five experiments, we investigated the power of targets defined by the onset or offset of one of an object's parts (contour onsets and offsets) either to guide or to capture visual attention. In Experiment 1 , search for a single contour onset target was compared with search for a single contour offset target against a static background of distractors; no difference was found between the efficiency with which each could be detected. In Experiment 2, onsets and offsets were compared for automatic attention capture, when both occurred simultaneously. Unlike in previous studies, the effects of overall luminance change, new-object creation, and number of onset and offset items were controlled. It was found that contour onset and offset items captured attention equally well. However, display size effects on both target types were also apparent. Such effects may have been due to competition for selection between multiple onset and offset stimuli. In Experiments 3 and 4, single onset and offset stimuli were presented simultaneously and pitted directly against one another among a background of static distractors. In Experiment 3, we examined "guided search," for a target that was formed either from an onset or from an offset among static items. In Experiment 4, the onsets and offsets were uncorrelated with the target location. Similar results occurred in both experiments: target onsets and offsets were detected more efficiently than static stimuli which needed serial search; there remained effects of display size on performance; but there was still no advantage for onsets. In Experiment 5, we examined automatic attention capture by single onset and offset stimuli presented individually among static distractors. Again, there was no advantage for onset over offset targets and a display size effect was also present. These results suggest that, both in isolation and in competition, onsets that do not form new objects neither guide nor gain automatic attention more efficiently than offsets. In addition, in contrast to previous studies in which onsets formed new objects, contour onsets and offsets did not reliably capture attention automatically.
\end{abstract}

\section{Automatic Attention Capture by Onsets and Offsets}

Visual stimuli can be presented in at least two ways. First, a stimulus can simply be presented in an unoccupied location by the illumination of its defining lines; this produces a rapid increase in luminance and is termed an onset stimulus. Alternatively, a premask stimulus can be displayed, sometime after which camouflaging lines are removed in order to reveal the stimulus item. This produces an overall luminance decrement (but the actual lines still defining the stimulus do not change luminance) and is termed an offset stimulus (Yantis \& Jonides, 1984).

Several researchers have assessed the ability of targets formed by onsets and offsets to capture attention automatically, and all have concluded that onsets dominate.

This work was supported by grants from the Medical Research Council of Great Britain, and from the Human Frontier Science Programme, to the second author. We would like to thank Steven Yantis, Arthur Kramer, and Jan Theeuwes for helpful comments and suggestions regarding this work. Correspondence should be addressed to D. G. Watson, Cognitive Science Research Centre, School of Psychology, University of Birmingham, Edgbaston, Birmingham, B 15 2TT England (e-mail: d.g.watson@bham.ac.uk).
Yantis and Jonides (1984) investigated the attentioncapturing power of onset stimuli in simple visual search tasks. Subjects had to indicate the presence or absence of a specified target letter among either two or four other letters arranged in various formations about a virtual hexagon. On each trial, the subject would be presented with the target letter, after which a display containing three box figure 8 premasks would be displayed. Following this, the premasks changed into various letters (E, H, P, S, or U) by the removal of camouflaging lines (offset stimuli) and at the same time a single letter would appear in what had been a blank location (the onset stimulus). On trials in which only two letters were presented, two of the premasks simply disappeared altogether. Subjects responded by pressing one of two keys to indicate the presence or absence of the target letter. The location of the target item was unrelated to the occurrence of an onset or offset, so subjects had no reason to try to attend selectively to either type of stimulus as opposed to the other. However, Yantis and Jonides found that when the target was formed by an onset, the reaction time (RT) to detect its presence was independent of the number of items in the display. In contrast, if the target was formed from one of the offsets, RTs increased with display size. This increase in RT as a function of the number of items 
present was found whether offset targets were formed by a gradual or an abrupt change.

Since subjects had no rationale for selectively attending to the onset stimulus, Yantis and Jonides (1984) suggested that the abrupt onset captured attention automatically. The onset element was always processed first, after which the other elements were searched serially.

Jonides and Yantis (1988) noted that in the Yantis and Jonides (1984) study an onset item might take attentional priority not because it was an onset but because, in the fouritem display, it was a unique event among three offset items. However, they found that in contrast to an onset item, an item in a search display that was unique in color or brightness did not capture attention automatically, in the sense that it was not always identified first. This suggests that, in previous studies, it was the property of being an abrupt onset that captured attention rather than the property of being a unique item in the display (see also Folk \& Annett, 1994; Todd \& Kramer, 1994).

Yantis and Johnson (1990) further found that in a field of multiple onsets and offsets, rather than onsets and offsets competing, approximately four onsets appeared to be processed before the offset elements. Yantis and Jones (1991) provided further evidence to suggest that multiple onset elements may be tagged with priority markers that decay over time, giving them search priority over offset elements.

\section{Luminance Changes and "New-Object" Differences}

Miller (1989) pointed out that the stimuli used by Yantis and Jonides (1984) resulted in an onset stimulus target creating a greater change in luminance than that created by the offset stimuli. Thus it may be that the greater overall change in luminance rather than the uniqueness of the abrupt onsets was responsible for capturing attention so effectively. To test this, Miller performed an experiment similar to those of Yantis and Jonides (1984), except that the figure of 8 premasks consisted of 11 segments rather than 7 . This made the luminance changes for onset and offset stimuli approximately equal. Miller found a significant effect of display size for both onset and offset targets. Nevertheless, onset targets were still detected significantly faster than offset targets and the effect of the display size was greater for the offset targets ( $45 \mathrm{vs}$. $26 \mathrm{msec}$ ), although this was only marginally significant $(p<.1)$. Miller concluded that neither onset nor offset targets pop out from a background containing offset distractors, when the total change in luminance between onsets and offsets is controlled for. Onset targets still have attentional priority over offset targets, however, and so they are detected more rapidly overall (Miller, 1989).

However, in addition to the luminance differences between onsets and offsets, the onset stimuli used by Yantis and Jonides (1984) also formed perceptually "new objects" by virtue of their appearing in previously unoccupied locations. In contrast, offset stimuli were formed by changing preexisting objects by removing line segments from them. Thus the previously observed priority for onset stimuli may reflect a priority for the visual system to attend to the appearance of new objects over changing objects. This new-object hypothesis has been examined by Yantis and Hillstrom (1994). They report that new objects (i.e., targets presented at previously unoccupied locations) defined by motion, texture, or binocular disparity (depth) capture attention effectively, even when luminance is kept constant. For example, the search slopes for equiluminant new-object stimuli were significantly smaller than for old-object (created from a premask) stimuli. Yantis and Hillstrom (contrary to Jonides \& Yantis, 1988) conclude that abrupt changes in luminance do not necessarily have special status for attentional capture; rather, it is the presence of new objects that gains high attentional priority (see also Hillstrom \& Yantis, 1994).

\section{Goal-Directed (Voluntary) Selection Versus Stimulus-Driven (Automatic) Selection}

The preceding studies were concerned with the ability of onsets to capture attention automatically. Since the onset stimulus was not correlated with the occurrence of the target, subjects had no rationale for selectively attending to the onset element. Yet it still captured attention before the offset stimuli did.

Folk, Remington, and Johnston (1992) have shown that if subjects are "set" to search for a particular feature that defines the target location reliably, that feature can be used to guide attention to the target item very efficiently. In particular, when subjects were set to search for a particular color, an invalid abrupt onset cue did not disrupt their performance but an invalid color cue did. Likewise, when subjects were searching for an abrupt onset, invalid color cues did not disrupt performance but invalid abrupt onset cues did. Folk et al. suggested that the exogenous attention control system may be "set" or "programmed" to respond to any particular feature. However, Yantis (1993) argues that because the subjects in Folk et al.'s study knew which feature defined the target on every trial, capture by that item was not necessarily automatic, since the subjects had "set" themselves to search for that feature. Thus the study shows only that features other than onsets can guide attention efficiently when subjects are "set" to use those features (see also Folk, Remington, \& Johnston, 1993). Note that, when attentional priority for onsets over offsets has been demonstrated without subjects being "set" for these stimuli, the presence of onset targets has been correlated with the appearance of new objects (see, e.g., Yantis \& Johnson, 1990; Yantis \& Jonides, 1984).

The main focus of the present paper was to evaluate the relative status of onsets and offsets that do not form new objects under both guided and nonguided search conditions. If, in previous studies, onsets captured attention over offsets because onsets alone formed new objects, onsets that do not also result in the formation of a new object should not take priority over offset stimuli. We examined these issues by comparing attention capture and guidance by what we shall term contour onsets and contour offsets to distinguish them from the new-object onsets used by previous 
researchers. A contour onset was formed by presenting a premask, to which line segments were added. This produced a luminance increase without also the accompanying new object of previous studies. A contour offset was formed by removing lines from a previously presented premask. ${ }^{1}$ If attentional priority is assigned to new objects over changing objects, and if the nature of the change effected on an existing object does not matter, contour onsets and contour offsets should be equivalent in their attention-capturing power under both goaldirected and stimulus-driven conditions.

\section{OVERVIEW OF EXPERIMENTS}

In Experiment 1, we examined and compared the detectability of single contour onset and contour offset targets under goal-directed search conditions when subjects were "set" to search for them. This experiment showed that goal-directed attention was equally efficient for both contour onsets and contour offsets. In Experiment 2, we measured stimulus-driven attention capture (automatic capture-in the absence of an attentional set) by presenting contour onset and contour offset stimuli simultaneously while controlling for luminance changes, creation of new objects, and number of onsets versus offsets. Again, no advantage was found for contour onset stimuli. However, RTs to both contour onset and contour offset targets also varied across display sizes. This might have been because of competition between onset and offset stimuli, with there being multiple onsets and offsets at the larger display sizes. In Experiments 3 and 4, we examined performance when a single onset and offset were pitted directly against each other. A single contour onset and contour offset occurred simultaneously along with static distractors. In Experiment 3, the target, when present, would be formed from either the onset or the offset and so subjects were "set" to attend to both types of change. In Experiment 4, target location was uncorrelated with the changing stimuli, and hence performance was measured under nonguided search conditions. In Experiment 5 , we assessed the automatic attention capture by single contour onset or offset stimuli presented individually against a static background of distractors. All three experiments showed that contour onsets were no more effective at guiding or capturing attention than contour offsets. Furthermore, they suggested that, unlike onsets that also form new objects, contour onsets (and offsets) do not reliably capture attention automatically.

\section{EXPERIMENT 1 \\ Goal-Directed Search for Contour Onset and Offset Targets}

In order to examine the detectability of contour onset and offset targets, we used a measure of attentional selection efficiency from visual search studies: whether target detection was influenced by the number of distractors in the display. The experiment was conducted in two parts, with different subjects in each part. In Exper- iment $1 \mathrm{~A}$, the subjects participated in two different conditions in which they searched for a target defined by a conjunction of color and form (Treisman \& Gelade, 1980). In one condition, the target was a blue $\mathrm{H}$ and the distractors were green Hs and blue As. In the other condition, the target was a blue $\mathrm{A}$ and the distractors were blue Hs and green As. These two conditions provided standard conjunction search baselines for the stimuli being used. The second part, Experiment 1B, also had two conditions - a contour onset and a contour offset condition. In the onset condition, green $\mathrm{A}$ and blue $\mathrm{H}$ distractors were presented alone for $100 \mathrm{msec}$, followed by (on target present trials) the addition of a top line segment to a blue $\mathrm{H}$ distractor to create a contour onset blue $\mathrm{A}$ target. In the offset condition, blue $\mathrm{A}$ and green $\mathrm{H}$ distractors appeared for $100 \mathrm{msec}$, after which the top line was removed from one of the blue A distractors to create an offset blue $\mathrm{H}$ target. Hence the size of any luminance change was equated for contour onset- and offset-based targets (cf. Miller, 1989). On absent trials in both conditions, neither an onset nor an offset occurred. Performance in the onset and the offset conditions was contrasted with that in the appropriate baseline conjunction conditions, in which a target was present from the onset of the whole display and was not defined by any unique luminance change.

\section{EXPERIMENT 1A Form-Color Conjunction Baseline Searches}

\section{Method}

Subjects. Ten undergraduate students ( 6 female, 4 male) at the University of Birmingham participated in one 50-min session for course credits or monetary payment. All were right-handed and had normal or corrected-to-normal vision.

Stimuli. All stimuli were generated and presented by an IBMPC-compatible computer driving a standard VGA graphics card attached to a super VGA monitor. Displays consisted of $1,4,8$, or 16 items arranged randomly within a $105-\mathrm{mm}$-high $\times 92-\mathrm{mm}-$ wide display area. The height of each stimulus was $7 \mathrm{~mm}$, and the width, $4 \mathrm{~mm}$. Subject viewing distance was $70 \mathrm{~cm}$.

Procedure. Each subject participated in two blocks of trials. In one block, they searched for the presence of a blue $\mathrm{H}$ among varying numbers of green $\mathrm{Hs}$ and blue As. In the other block, they searched for a blue $\mathrm{A}$ among blue $\mathrm{Hs}$ and green As. A trial consisted of a central fixation cross for $1,500 \mathrm{msec}$ and then the search display. The order of the blocks was counterbalanced across subjects. Each block consisted of a total of 160 trials, the target was present on half the trials, and there was an equal number of trials for each of the 4 display sizes, with $1,4,8$, and 16 items, respectively. Half the subjects pressed key $Z$ if the target was present and $M$ if it was absent, and this was reversed for the other half. Before each block, subjects were given a short block of practice trials which contained a representative sample of the displays they were to see.

\section{Results and Discussion}

Descriptive statistics for the search functions for each condition are given in Table 1. Mean correct RTs were analyzed in two separate two-way within-subjects analyses of variance (ANOVAs), with target (present/absent) and display size as the main factors.

For blue $\mathrm{H}$ targets among green $\mathrm{Hs}$ and blue As, there was a significant effect of target present/absent $[F(1,9)=$ 
Table 1

Statistics for the Search Functions for Each Condition in Experiment 1A

\begin{tabular}{lccccc}
\hline Target & $M$ & Intercept & Slope & $\begin{array}{c}\text { \% Variance Attributable } \\
\text { to the Linear Component } \\
\text { of the Search Function }\end{array}$ & $\begin{array}{c}\text { Present:Absent } \\
\text { Slope }\end{array}$ \\
\hline \multicolumn{7}{c}{$\begin{array}{l}\text { Search for Blue H Target Versus Green H and Blue A Distractors } \\
\text { Absent }\end{array}$} & 983 & 509 & 65.4 & 99.9 & 1.85 \\
Present & 771 & 514 & 35.4 & 98.8 & 1.50 \\
& Search for Blue A Target Versus Green A and Blue H Distractors \\
Absent & 968 & 554 & 57.1 & 100 & \\
Present & 827 & 552 & 38 & 97.4 & \\
\hline
\end{tabular}

Note-Mean and intercept are given in milliseconds; slope, in milliseconds per item.

$\left.130.3, M S_{\mathrm{e}}=6,904, p<.001\right]$ and of the number of items in the display $\left[F(3,27)=89.86, M S_{\mathrm{e}}=23,900, p<.001\right]$; there was also a reliable display size $\times$ present/absent interaction $\left[F(3,27)=85.67, M S_{\mathrm{e}}=2,277, p<.001\right]$. The linear components accounted for the majority of variance on both present and absent trials; the search rates for present and absent trials were 65.4 and $35.4 \mathrm{msec} /$ item, giving a present:absent slope ratio of 1:1.85.

For a blue A among blue $\mathrm{Hs}$ and green As, there were significant effects of target present/absent $[F(1,9)=$ $\left.29.28, M S_{\mathrm{e}}=13,591, p<.001\right]$ and number of items in the display $\left[F(3,27)=127.93, M S_{\mathrm{e}}=15,002, p<.001\right]$, and there was a present/absent $\times$ display size interaction $\left[F(3,27)=14.07, M S_{\mathrm{e}}=6,171, p<.001\right]$. Again the search functions for blue $A$ present and absent trials were largely accounted for by linear functions. Search rates on absent and present trials were 57.1 and $38.0 \mathrm{msec} /$ item, respectively, giving a present:absent slope ratio of 1:1.5.

\section{EXPERIMENT 1B Contour Onset- and Offset-Based Targets}

\section{Method}

Subjects. Eleven undergraduate students ( 6 female, 5 male) at the University of Birmingham participated in one 50-min session for course credits or monetary payment. All had normal or correctedto-normal vision.

Stimuli and Procedure. The stimulus displays and procedure were essentially the same as in Experiment $1 \mathrm{~A}$, with the following exceptions. In the offset condition, between 1 and 16 distractor items (blue As and green $\mathrm{Hs}$ ) were displayed following a $1,500-\mathrm{msec}$ fixation cross. On half the trials within $100 \mathrm{msec}$, one of the blue As turned into a blue $\mathrm{H}$ by the removal of one of its defining line segments. On the other half (absent trials), no change occurred. The subjects indicated whether a blue $H$ was present or absent by pressing one of two keys ( $Z$ or $M$ ). The other block (onset condition) was essentially the same, except that the distractors were blue Hs and green As and the change, if present, consisted of a blue $\mathrm{H}$ turning into a blue $\mathrm{A}$ by the addition of one defining line segment. The subjects indicated whether a blue A was present or absent.

\section{Results}

Descriptive statistics for the contour onset and offset conditions are given in Table 2. Error rates in this and all the other experiments were low and will not be reported any further unless they traded off with RTs.

Contour offset condition. There were significant effects of target present/absent $\left[F(1,10)=11.60, M S_{\mathrm{e}}=\right.$ $123,708, p<.01]$ and display size $[F(3,30)=5.03$, $\left.M S_{\mathrm{e}}=26,101, p<.01\right]$, and there was a reliable display size $\times$ present/absent interaction $[F(3,30)=4.25$, $\left.M S_{\mathrm{e}}=22,032, p<.05\right]$. The slope of the search on absent trials was $21.7 \mathrm{msec} / \mathrm{item}$, and on present trials it was $1.96 \mathrm{msec} /$ item.

Contour onset condition. There were reliable effects of target present/absent $\left[F(1,10)=51.61, M S_{\mathrm{e}}=\right.$ $10,211, p<.001]$ and display size $[F(3,30)=8.67$, $\left.M S_{\mathrm{e}}=4,260, p<.001\right]$, and there was a reliable display size $\times$ present/absent interaction $[F(3,30)=7.99$, $\left.M S_{\mathrm{e}}=5,381, p<.001\right]$. The slope of the search function for absent trials was $12.2 \mathrm{msec} / \mathrm{item}$ and for present trials it was $-0.07 \mathrm{msec} /$ item.

Contour onset versus offset targets. A two-way within-subjects ANOVA was employed to compare RTs for contour onset and offset targets on present trials only. There was no significant effect of display size $[F(3,30)=$ $1.69, p=.191]$, no difference between RTs to contour onset and offset targets $[F(1,10)=1.41, p=.263]$, and no interaction $[F(3,30)=0.96, p=.426]$.

Comparisons with baseline conditions. The onset and offset conditions were compared with their respective baseline conditions in a three-way ANOVA with condition (baseline vs. contour onset or offset condition) as a between-subjects factor and target present/absent and display size as within-subjects factors.

For the offset condition, all three main effects were significant: condition $\left[F(1,19)=13.392, M S_{\mathrm{e}}=316,013\right.$, $p<.005]$, target present/absent $[F(1,19)=33.485$, $\left.M S_{\mathrm{e}}=68,379, p<.001\right]$, and display size $[F(3,57)=$ $\left.68.438, M S_{\mathrm{e}}=25,059, p<.001\right]$. There were also significant interactions of display size $\times$ condition $\left[F(3,57)=26.384, M S_{\mathrm{e}}=25,059, p<.001\right]$, and target present/absent $\times$ display size $\left[F(3,57)=22.209, M S_{\mathrm{e}}=\right.$ $12,675, p<.001]$. The interaction between target present/absent and condition did not reach significance $[F(1,19)=0.288]$, nor did the three-way interaction $[F(3,57)=0.959]$. Overall, RTs were faster in the con- 
Table 2

Statistics for the Contour Onset and Offset Conditions in Experiment 1B

\begin{tabular}{|c|c|c|c|c|c|}
\hline Target & $M$ & Intercept & Slope & $\begin{array}{l}\% \text { Variance Attributable } \\
\text { to the Linear Component } \\
\text { of the Search Function }\end{array}$ & $\begin{array}{l}\text { Present:Absent } \\
\text { Slope } \\
\end{array}$ \\
\hline \multicolumn{6}{|c|}{ Search for Offset Blue H Target Versus Blue A and Green H Distractors } \\
\hline $\begin{array}{l}\text { Absent } \\
\text { Present }\end{array}$ & $\begin{array}{l}687 \\
431\end{array}$ & $\begin{array}{l}530 \\
417\end{array}$ & $\begin{array}{l}21.7 \\
1.96\end{array}$ & $\begin{array}{l}98.1 \\
82.4\end{array}$ & 11.07 \\
\hline \multicolumn{6}{|c|}{ Search for Onset Blue A Target Versus Blue H and Green A Distractors } \\
\hline $\begin{array}{l}\text { Absent } \\
\text { Present }\end{array}$ & $\begin{array}{l}643 \\
488\end{array}$ & $\begin{array}{l}554 \\
489\end{array}$ & $\begin{array}{l}12.2 \\
-0.07\end{array}$ & $\begin{array}{r}88.9 \\
0.1\end{array}$ & $-174,29$ \\
\hline
\end{tabular}

Note-Mean and intercept are given in milliseconds; slope, in milliseconds per item.

tour offset condition and display size had a much smaller effect on RTs in the offset condition than in the standard conjunction search baseline condition.

For the contour onset condition, exactly the same pattern of results emerged. All three main effects reached significance: condition $\left[F(1,19)=13.443, M S_{\mathrm{e}}=343,580\right.$, $p<.005]$, target present/absent $[F(1,19)=77.614$, $\left.M S_{\mathrm{e}}=11,812, p<.001\right]$, and display size $[F(3,57)=$ $\left.136.727, M S_{\mathrm{e}}=9,349, p<.001\right]$. There were also significant interactions of display size $\times$ condition $[F(3,57)=$ $\left.82.101, M S_{\mathrm{e}}=9,349, p<.001\right]$, and target present/ absent $\times$ display size $\left[F(3,57)=21.222, M S_{\mathrm{e}}=5,755\right.$, $p<.001]$. The interaction of target present/absent and condition did not reach significance $[F(1,19)=0.167]$, nor did the three-way interaction $[F(3,57)=1.705]$. RTs were faster in the contour onset condition and display size had a much smaller effect on RTs in the onset condition than in the standard conjunction search baseline condition.

\section{Discussion}

In the baseline conditions, performance matched that found in several studies of search for targets defined by conjunctions of color and form: RTs on present and absent trials increased linearly with the display size, the ratios of the search functions on present and absent trials approximated 1:2, and present slopes were over $30 \mathrm{msec} /$ item (see Quinlan \& Humphreys, 1987; Treisman \& Gelade, 1980). When the same targets were signaled by the detection of either the onset or the offset of a line feature in a distractor, performance was dramatically different; now there were no effects of display size on target detection. The search functions for the standard baseline conditions are consistent with serial search, whereas for targets defined by contour onsets and offsets the functions indicate parallel detection.

These results demonstrate that contour offsets can be searched for and detected in parallel, and that this parallel detection can be as efficient as that for contour onset targets (indeed, there was a trend for offset targets to be detected more efficiently than onset targets). In all other previous studies, when the onset item has also formed a new object, an advantage has been observed for the onset as opposed to the offset stimuli (Yantis \& Jonides, 1984), even when overall luminance changes have been equated (Miller, 1989). This prior advantage could have been due either to onset targets alone comprising new objects, or to offset targets having to compete with other offset distractors. In Experiment 1B, there was only ever one contour onset or one offset in a display of static elements, and subjects knew whether the target would be a contour onset or offset. It is possible that onsets may only dominate offsets when both onsets and offsets are presented simultaneously or when subjects are not specifically searching for onsets or offsets (i.e., onsets may dominate offsets only for automatic attention capture, not goal-directed search).

Although the data from Experiment 1 show that contour offset targets can be detected as efficiently as contour onset targets under optimal conditions, they do not show that the efficiency of detecting contour onset targets is equal to that for offset targets when the stimuli are presented simultaneously - when they may compete for attention. In the studies of Yantis and Jonides (1984) and Miller (1989), a single onset was presented with one or several offset stimuli, and it was found that the onset element dominated attention capture, even though the target was equally likely to have been any of the displayed elements. Since the target was equally likely to have been an onset or an offset element, subjects may have consciously searched for both onsets and offsets or for neither (i.e., either both onsets and offsets were in the observer's attentional set or neither were). Whichever was true, the results suggest that either (1) when subjects are set to search for both onsets and offsets, the onset will take priority, or (2) when subjects are not set to search for any particular feature, onsets still dominate.

The conditions in Experiment 2 were similar to the original ones in Yantis and Jonides (1984), except that we used contour onsets rather than new-object onsets and there was always an equal number of onsets and offsets in the display. The subjects were presented with displays containing either one target and one distractor (two-item displays) or one target and three distractors (four-item displays). In two-item displays, a contour onset target was always displayed with a contour offset distractor and vice versa for offset targets. In four-item displays, two-onset and two-offset stimuli were always presented. The subjects made a forced-choice response to the identity of the target. As in the studies of Yantis 
and others with this procedure, the target was equally likely to be an onset or an offset element, so subjects should again search for either both onsets and offsets or neither. However, in our paradigm, neither onsets nor offsets formed new objects, and there were always equal numbers of onset and offset distractors.

Dominance for onset stimuli will be shown by faster RTs to onset than to offset targets and by onset targets' being less affected by the number of items in the displays.

\section{EXPERIMENT 2 Automatic Attention Capture by Contour Onsets and Offsets}

\section{Method}

Subjects. Six female and 4 male undergraduate students at the University of Birmingham participated for partial fulfillment of a course requirement, money, or a combination of both. The rate of payment was $£ 2.00$ per hour. All subjects were right-handed and had normal or corrected-to-normal vision.

Stimuli. All stimuli were generated and presented by an IBMPC-compatible computer driving a standard VGA graphics card attached to a super VGA monitor. Stimuli were presented in highcontrast white against a black background. The premasks consisted of box figure $8 \mathrm{~s}$, as in the experiments of Yantis and Jonides (1984), and Ts rotated $90^{\circ}$ counterclockwise. The offset distractor stimuli consisted of the uppercase letters $S$ and $U$, formed by removing two lines from the figure 8 premasks. The onset distractors were the letters $P$ and lowercase $b$, formed by adding two lines to the rotated $T$ premasks. The target stimuli were the letters $E$ and $\mathrm{H}$, which could be formed by adding or removing two lines from the rotated T or figure 8 premasks, respectively, and could thus be formed from an onset or offset. Each letter was $12 \mathrm{~mm}$ in height and $7 \mathrm{~mm}$ in width.

Design. A $2 \times 2$ design was employed, the factors being the target type (onset/offset) and the number of letters in the search display (two or four). Each trial consisted of four phases: a blank screen $(1 \mathrm{sec})$, followed by a central fixation cross $(1 \mathrm{sec})$, the premask display ( $1 \mathrm{sec}$ ), and the search display (see Figure 1). The premask display always consisted of four items, two figure 8 premasks and two rotated Ts. These were arranged at the corners of a virtual square ( $45-\mathrm{mm}$ inner dimensions). There were four possible arrangements of the premasks as follows: T88T, TT88, 88TT, or 8T8T in the upper left, upper right, lower left, or lower right corners of the box. The four-item search display was formed by turning one of the premasks into a target $(\mathrm{E}$ or $\mathrm{H})$ and the remainder into distractor letters. The two-item search displays were formed by turning a premask into a target and only one of the other premasks into a distractor; the remaining two premasks disappeared. The target side, left/right, was chosen randomly. In the case of the two-item search display, if the target was an onset, the distractor was an offset and vice versa, so there were always at least one onset and one offset item. For four-item displays, there were always two onsets and two offsets present. The target type (onset/offset), its identity $(\mathrm{E} / \mathrm{H})$, and the initial premask formation were completely balanced. The order of trials (target identity, target type, and number of items in the search display) was random within a block of trials.

Procedure. Each subject participated in a total of three blocks of trials in one 50-min session. Each block consisted of 128 trials. The subjects sat approximately $60 \mathrm{~cm}$ from the computer screen, which was at eye level. Each trial consisted of a blank screen ( $1 \mathrm{sec}$ ), a central fixation cross ( $1 \mathrm{sec}$ ), the premask display ( $1 \mathrm{sec}$ ), and the search display. The search display remained until the subject made a response. The subjects responded by pressing the "." key with the right index finger if the letter $H$ was present or the " $/$ " key with the right middle finger if the letter $E$ was present. Immediate error feedback was provided by a $500-\mathrm{msec} 1000-\mathrm{Hz}$ tone. The subjects were instructed to respond as quickly and accurately as possible, that the $E$ and $H$ targets would be present equal numbers of times, but that their positions would be random within the four possible display positions.

\section{Results}

Mean correct RTs and total number of errors were calculated for each subject. The overall means of these values as a function of target type (onset/offset) and display size (2/4) are shown in Figure 2.

RTs. A two-way within-subjects ANOVA revealed a significant main effect of display size $[F(1,9)=14.99$, $\left.M S_{\mathrm{e}}=2,011, p<.01\right]$ : it took longer to identify a target when there were four items than when there were only two items in the display. There was an overall trend for contour onset targets to be detected more quickly than offsets (the main effect of target type, onset vs. offset), but this was small in absolute terms $(12 \mathrm{msec})$ and did not approach significance $\left[F(1,9)=1.32, M S_{\mathrm{e}}=1,146\right.$, $p=.28]$. Also, overall, only 5 of the 10 subjects showed this trend, with the remainder showing the opposite trend. There was also no sign of an interaction between display size and target type $\left[F(1,9)=0.81, M S_{\mathrm{e}}=433\right.$, $p=.391]$. The slopes of the functions were $24.45 \mathrm{msec}$ per item for the offset targets and $30.45 \mathrm{msec}$ per item for the onset targets.

Errors. The error rates were $1.98 \%$ and $3.02 \%$ for offsets and $1.04 \%$ and $2.40 \%$ for onsets at display sizes 2 and 4 , respectively. A two-way within-subjects ANOVA was performed on the mean total errors per subject. Dis-

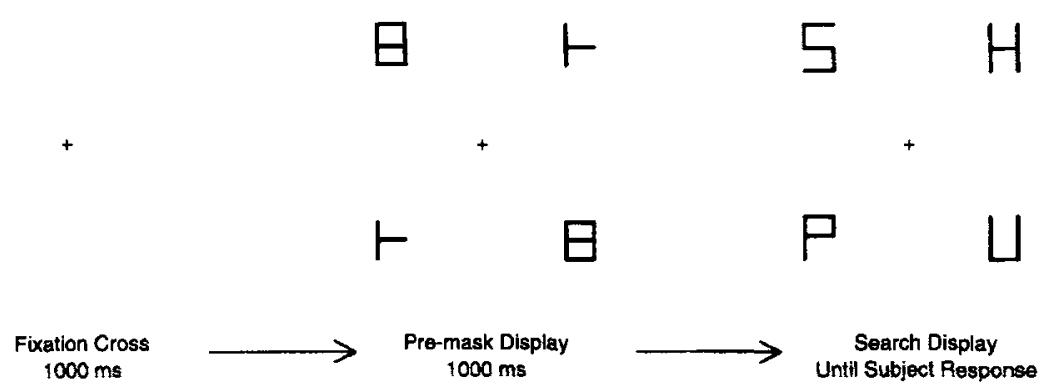

Figure 1. The sequence of displays in a single trial from Experiment 2. 


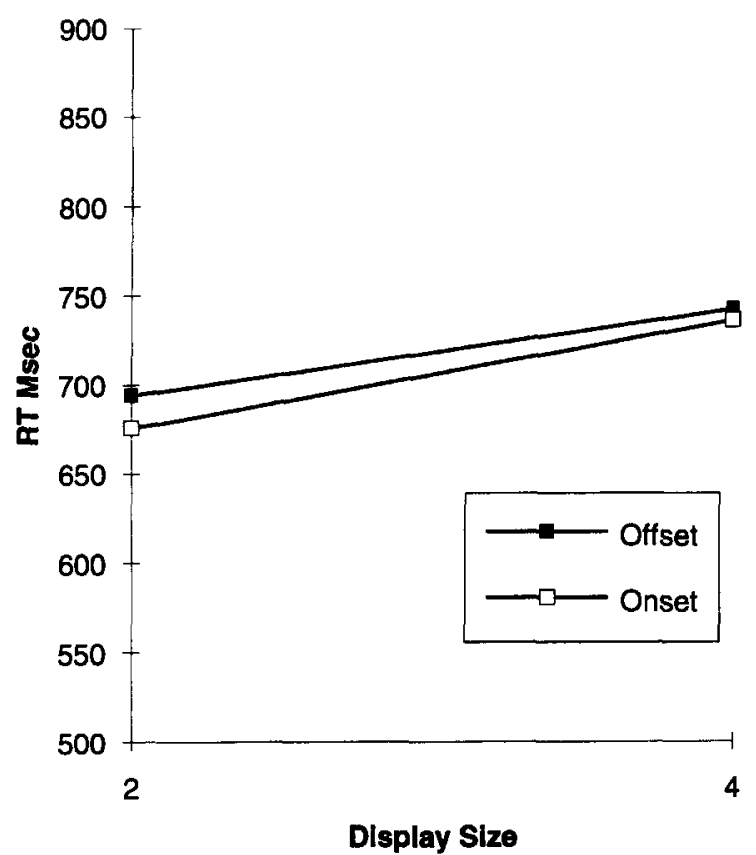

Figure 2. Mean correct reaction time to indicate the presence of a target as a function of its presentation (onset/ofiset) and display size.

play size affected the error rate $\left[F(1,9)=5.53, M S_{\mathrm{e}}=\right.$ $2.4, p<.05]$. Neither the main effect of target type (onset or offset) $\left[F(1,9)=1.74, M S_{\mathrm{e}}=3.2, p=.22\right]$ nor the target type $\times$ display size interaction approached significance $\left[F(1,9)=0.1, M S_{\mathrm{e}}=2.2, p=.755\right]$.

\section{Discussion}

With onsets and offsets matched for the overall size of any luminance changes, and when both onset and offset targets occurred at previously occupied locations (the onset did not form a new object), there was no difference in identification for targets defined by onsets and those defined by offsets. Also, both onset and offset targets showed effects of display size on identification.

The closest study in the literature to Experiment 2 is probably that of Miller (1989), who also equated onset and offset targets for luminance change. As previously noted, he, like us, found that identification of both types of target was affected by the number of elements in the display; however, he also found an overall RT advantage for onset targets and that onset targets showed a smaller display size effect. We have shown that any advantage for onset targets over offset targets can be eliminated when the targets are matched for luminance change and neither forms new objects.

One other difference between Experiment 2 and prior studies with an identification procedure is that in our four-item displays, subjects were presented with two onset as well as multiple offset stimuli. The display size effects that we observed with onset targets may have occurred because with four-item displays, onset targets had to compete with onset distractors, demanding the same processing mechanisms. However, note that the use of onset distractors in the four-item displays cannot explain the lack of onset dominance with two-item displays (where onset targets were presented along with offset distractors, and vice versa). The data obtained with the two-item displays indicate that there is no advantage for onset targets, even in identification tasks, when luminance and the presence of new objects are controlled for. Also, in other studies in which multiple new-object onsets have been displayed with multiple offsets, multiple onsets appeared not to compete for attention but rather to be tagged to receive attentional priority over the offsets (Yantis \& Johnson, 1990; Yantis \& Jones, 1991).

The present results demonstrate that when simultaneously presented onsets and offsets are equated with respect to luminance changes and the creation of new objects, onsets do not dominate offsets for the capture of attention.

It is possible that in this situation, onsets and offsets effectively cancel each other out; neither capture attention. Alternatively, both onset and offset stimuli may be tagged for attentional priority simultaneously but neither dominate the other. In Experiment 3, we investigated this by using a goal-directed search task in which both a single contour onset and a single contour offset stimulus was always present, and the target could be either the onset or the offset element equally often. Since in this case onset and offset stimuli were directly pitted against one another, the study assessed the power of each property to guide attention without confounding between multiple onsets and multiple offsets (cf. Experiment 2). Also this study included a standard baseline condition (in which the target was a static stimulus rather than an offset or onset stimulus), enabling us to assess whether the contour onset and offset targets would capture attention under goal-directed conditions.

\section{EXPERIMENT 3 \\ Competition Between Single Onsets and Offsets Among Static Distractors During Goal-Directed Search}

The subjects searched for the presence or absence of a letter $A$ among $n, O$, and figure 8 distractors formed by illuminating segments of a box figure 8 . There were two conditions. In one condition (the standard conjunction condition), the distractors and the target (if present) were displayed simultaneously. This condition served as a baseline and to determine whether the stimuli used would ordinarily produce serial search.

In the other condition (onset/offset condition), a display containing only the distractors was initially displayed, and after $100 \mathrm{msec}$, a single contour onset and a single offset occurred simultaneously. The onset and offset were formed by adding and removing one line segment from two of the initially displayed distractors and so produced equal luminance changes and no new objects. On target absent trials, both the onset and offset 
formed distractors. On "target present onset trials," the target was formed by the onset, and the offset formed a distractor, and on "target present offset trials," the offset formed the target and the onset formed a distractor. The target was equally likely to be formed from either the onset or the offset element and if present would always be either the onset or the offset element, so it was advantageous for subjects to try to attend equally to these events.

Several findings were possible: (1) The onset and offset stimuli might cancel each other out, making search no more efficient in the onset/offset condition than in the standard conjunction baseline condition. (2) Subjects might only be able to attend selectively to the onset, in which case search for an onset target would be more efficient than in the standard conjunction condition; the offset target would produce performance similar to the standard conjunction baseline. (3) The opposite might occur, in which case search would be more efficient than in the baseline condition when the target was an offset but not when it was an onset. (4) Both onset and offset stimuli might enter into a queue or be tagged for attentional priority with the onset taking top priority. In this case, both onset and offset target trials would have a smaller search slope than would the baseline condition, but the mean RT for the onset would be faster than for the offset. (5) Both onset and offset stimuli might be queued/tagged, but neither might take priority. In this case, search would be more efficient for both onsets and offsets in comparison with the baseline conjunction condition, but there would be no difference between the onset and offset target trials. Finally, (6) either the onset or the offset might be tagged for priority but not both; in this case, after examining the selected onset or offset, the remaining items might be treated with equal priority. This would result in present trials for onset and offset targets that were on the average twice as fast as those in the baseline, since the target would be the single onset or offset item that was examined first on $50 \%$ of the trials.

\section{Method}

Subjects. Twelve subjects ( 1 male and 11 female) between 18 and 48 years of age (mean, 23.1) were paid to participate in this study. All were students at the University of Birmingham and had self-reported normal or corrected-to-normal vision.

Stimuli. The stimuli consisted of a white $A$ target with white $n$, $\mathrm{O}$, and figure 8 distractors. The stimuli were formed by illuminating segments of a box figure 8 and fell randomly within an $80-\mathrm{mm}-$ high $\times 60$-mm-wide display area. Individual stimuli were $7 \mathrm{~mm}$ high $\times 4 \mathrm{~mm}$ wide. The display size was 6,9 , or 12 items, and the target was present on $50 \%$ of the trials. All stimuli were generated and presented by an IBM-PC-compatible computer driving a standard VGA graphics card attached to a super VGA monitor. The subject viewing distance was approximately $70 \mathrm{~cm}$. The features present in the target were present across the set of distractors used, so that the target was defined by the particular conjunction of form features present (cf. Humphreys, Quinlan, \& Riddoch, 1989). This assumption was verified by the search results.

There were two main conditions: a standard conjunction condition used as a baseline measure and an onset/offset condition. A trial in the conjunction baseline condition consisted of the presentation of a blank screen for $500 \mathrm{msec}$, followed by a central fixation cross for $1,000 \mathrm{msec}$ and then the search display, which remained on until subjects responded whether the target was present or absent. On target absent trials, there were an equal number of $\mathrm{n}, \mathrm{O}$, and figure 8 distractor items, and on target present trials, the target took the place of an n or an 8 distractor equally often. The subjects indicated the presence or absence of the target by pressing either " $z$ " or " $m$ " on a standard computer keyboard. Response keys were counterbalanced across subjects. Immediate error feedback was given by the presentation of a $500-\mathrm{Hz}$ tone for $500 \mathrm{msec}$ on incorrect trials, after which the display blanked and the next trial began.

The onset/offset condition was similar, except that following the fixation cross, a display containing only the distractor items was displayed, and after $100 \mathrm{msec}$, both an onset and an offset occurred. On target absent trials, an $O$ distractor changed to an 8 distractor through the addition of one line segment (to form an onset distractor) and an 8 distractor changed to an $O$ distractor through the removal of one segment (to form an offset distractor). On onset target present trials, an $\mathrm{O}$ changed to an $\mathrm{n}$ through the removal of one segment (offset distractor) and an $\mathrm{n}$ changed to an A through the addition of a line segment (onset target). On offset target present trials, an $O$ changed to an 8 (onset distractor) and an 8 changed to an A (offset target). Thus, in this condition there were three main types of trials: (1) absent trials in which the onset and offset formed distractors, (2) present trials in which the target was formed from an onset and the offset formed a distractor, and (3) present trials in which the target was an offset and the onset formed a distractor.

Procedure. The two conditions (conjunction baseline and onset/ offset condition) were presented in different blocks of trials. Each block contained 120 trials in a randomized order. Within one block were equal numbers of target present and absent trials at each display size $(6,9,12)$. In the onset/offset blocks, the present trials were further divided into equal numbers of target onset and target offset trials. Following a short practice block for both conditions, each subject then completed two blocks of each condition in an ABAB design counterbalanced across subjects in a single session lasting approximately $1 \mathrm{~h}$.

\section{Results}

The two blocks of trials for each condition for each subject were combined and the means calculated by using RTs on correct trials only. Figures $3 \mathrm{~A}$ and $3 \mathrm{~B}$ show the mean correct RTs for display size and target presence/ absence for each condition. Full descriptive statistics for the search slopes are given in Table 3.

We were interested primarily in two comparisons: (1) whether target detection would be more efficient in the onset/offset condition than in the standard conjunction condition, and (2) whether, in the onset/offset condition, there would be a difference between when the target was formed from an onset and when it was formed from an offset. Initially, however, each condition was analyzed individually, to determine whether the standard conjunction condition and/or the onset/offset condition produced data typical of conjunction search.

Standard conjunction condition. RT data for correct trials only were entered into a two-way within-subjects ANOVA with target (present/absent) and display size as the main factors. This revealed significant main effects of target $\left[F(1,11)=56.91, M S_{\mathrm{e}}=24,669, p<.001\right]$ and 

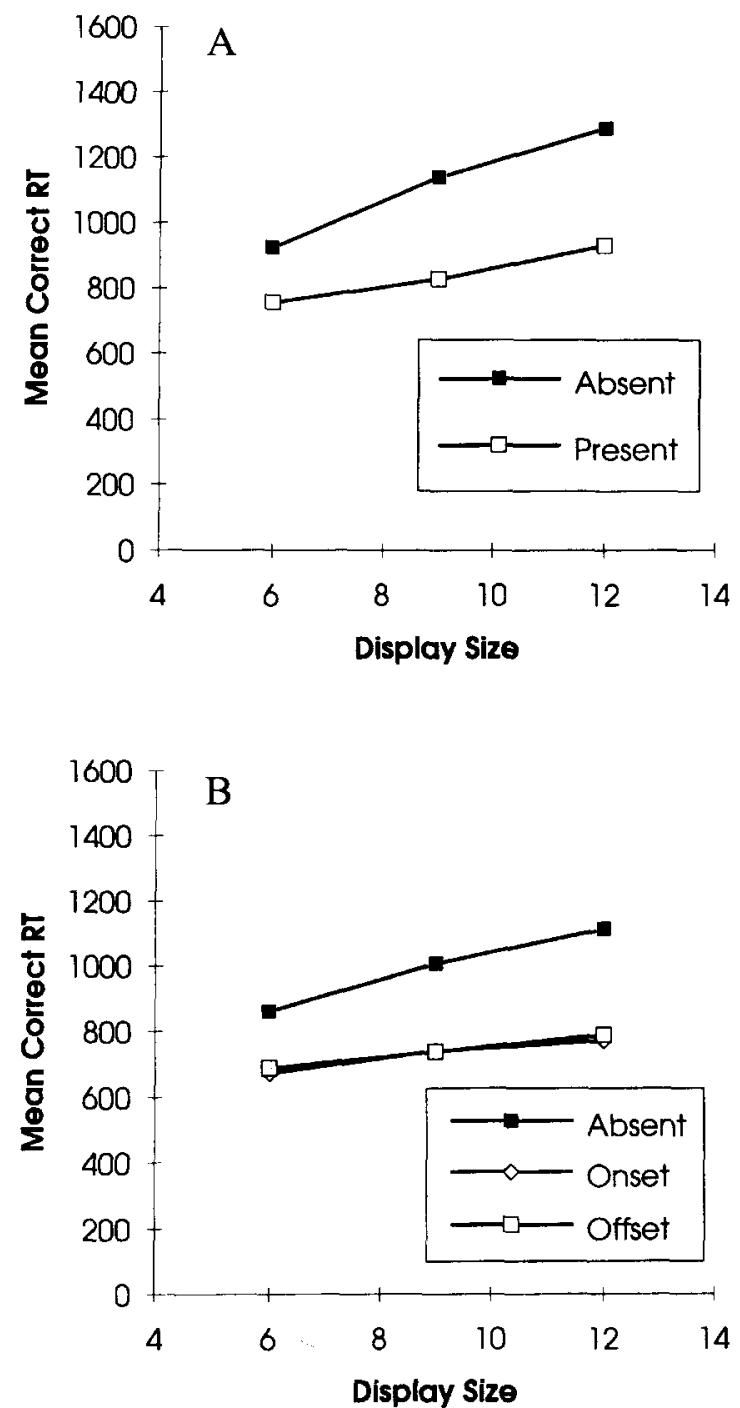

Figure 3. (A) Mean correct reaction time to indicate the presence/absence of a box letter $A$ target among block figure ns, $O$ s, and 8 s as a function of display size. (B) Mean correct reaction time to indicate the presence/absence of a box letter $A$ target reliably formed from an onset or ofiset among block figure $\mathrm{ns}, \mathrm{Os}$, and $8 \mathrm{~s}$ as a function of display size.

display size $\left[F(2,22)=73.33, M S_{\mathrm{e}}=5,938, p<.001\right]$ and a significant target $\times$ display size interaction $\left[F(2,22)=28.09, M S_{\mathrm{e}}=2,068, p<.001\right]$. As can be seen in Figure 3A, present RTs were faster than absent, RTs increased with display size, and absent RTs increased more with display size than did present RTs. The slope ratio for present:absent trials was 1:2.07.

Onset/offset conjunction. RT data for correct trials only were entered into a two-way within-subjects ANOVA with target (onset/offset/absent) and display size as the main factors. This also revealed significant main effects of target $\left[F(2,22)=28.65, M S_{\mathrm{e}}=28,234, p<\right.$ $.001]$ and display size $\left[F(2,22)=32.54, M S_{\mathrm{e}}=6,347\right.$, $p<.001]$ and a significant target $\times$ display size interaction $\left[F(4,44)=10.88, M S_{\mathrm{e}}=2,163, p<.001\right]$. As can be seen in Figure 3B, again present RTs were faster than absent, RTs increased with display size, and absent RTs increased more with display size than did present RTs. Present:absent slope ratios were $1: 2.53$ and $1: 2.5$ for onset and offset targets, respectively.

The results from both the standard conjunction and the onset/offset conditions suggest serial search; both show increased RTs with display size, and absent trials increase more with display size than do present trials. However, as can be seen in Table 3, search slopes in the onset/offset condition were approximately half those of the standard conjunction condition. These differences were tested in two separate two-way within-subjects ANOVAs, in order to compare the present and absent trials across the two conditions.

Absent trials. Data for the absent trials from each condition were analyzed in a two-way within-subjects ANOVA with condition (standard vs. onset/offset absent trials) and display size as the main factors. This revealed significant main effects of condition $[F(1,11)=10.92$, $\left.M S_{\mathrm{e}}=24,618, p<.01\right]$ and display size $[F(2,22)=$ $\left.72.37, M S_{\mathrm{e}}=7,920, p<.001\right]$ and a significant condition $\times$ display size interaction $\left[F(2,22)=7.44, M S_{\mathrm{e}}=\right.$ $2,547, p<.005]$. RTs were faster, and the slope of the search function was smaller in the onset/offset condition than in the baseline.

Present trials. The data from the present trials in each condition were analyzed as above, with the main factors being condition (baseline condition present vs. onset present vs. offset present) and display size. This again revealed significant main effects of condition' $\left[F(2,22)=39.59, M S_{\mathrm{e}}=3,205, p<.001\right]$ and display size $\left[F(2,22)=29.98, M S_{\mathrm{e}}=4,716, p<.001\right]$ and a significant condition $\times$ display size interaction $[F(4,44)=$ $\left.3.89, M S_{\mathrm{e}}=1,748, p<.01\right]$. RTs in the onset/offset condition were again faster than in the standard condition and were less affected by display size. Search was more efficient in the onset/offset condition.

Finally, target present trials when the target was formed from an onset were compared with those when the target was formed from an offset, using a two-way within-subjects ANOVA with the main factors of target (onset vs. offset) and display size. This revealed a significant effect of display size $\left[F(2,22)=19.42, M S_{\mathrm{e}}=\right.$ $3,137, p<.001]$; but the effect of target did not approach significance $\left[F(1,11)=1.06, M S_{\mathrm{e}}=1,935, p=.324\right]$, nor did the target $\times$ condition interaction $[F(2,22)=$ $\left.0.51, M S_{\mathrm{e}}=1,391, p=.607\right]$. Contour onset and offset targets were equally effective for guiding attention.

\section{Discussion}

We were interested in whether subjects could attend selectively to both a contour onset and a contour offset stimulus with equal priority when set to search for both. The results showed that search was more efficient when the target was formed from either an onset or an offset than it was in the standard conjunction search condition. This indicates that subjects were sensitive to the occurrence of onsets and offsets and could use either change to 
Table 3

Experiment 3: Search for an A Target Among $n, O$, and

Figure 8 Distractors

\begin{tabular}{lcccccc}
\hline & \multicolumn{3}{c}{$\begin{array}{c}\text { Standard } \\
\text { Conjunction }\end{array}$} & & \multicolumn{3}{c}{ Onset/Offset Conjunction } \\
\cline { 2 - 3 } \cline { 5 - 7 } & Absent & Present & & Absent & Present Onset & Present Offset \\
\hline Intercept & 571 & 574 & & 616 & 579 & 588 \\
Slope & 60.5 & 29.2 & & 42 & 16.6 & 16.8 \\
$R^{2}$ & 98.9 & 98.7 & & 99.2 & 96.3 & 100 \\
Absent:present ratio & & 2.07 & & 2.53 & 2.50 \\
\hline
\end{tabular}

Note-Intercept is given in milliseconds; slope, in milliseconds per item.

guide attention to the target. Also onset and offset targets showed no difference in their power to guide attention.

The evidence indicates that onset and offset targets were assigned a higher priority than were other items in the displays, since performance was overall faster and search slopes lower with the former targets. Nevertheless, there remained reliable effects of display size on performance, even with onset and offset targets. This is of some interest, because single targets defined by onsets and by offsets similar to those in Experiment 3 could be detected irrespectively of the display size in Experiment 1 . This suggests that there may have been costs to performance from having both an onset and an offset stimulus in each display. Indeed, the search slopes for present trials in the onset and offset conditions were approximately half those in the standard conjunction condition. This is consistent with only one item's being assigned high priority, and with all other items receiving equal priority for search. This hypothesis could be assessed by examining the distributions of RTs for present trials (Yantis, Meyer, \& Smith, 1991). In contrast to the baseline condition, trials in the onset/offset condition should contain a mixture of fast RTs (when the item examined with priority was the target) and slower RTs (when the prioritized item was not the target and a serial search was then required). However, there were insufficient trials in Experiment 3 to allow such an analysis.

At least two possible accounts can be offered for the present result. One possibility is that subjects have both onsets and offsets in their attentional set and search for both types of target simultaneously; both the onset and the offset stimulus are tagged for search priority on each trial. The order in which they are then examined is random, but after one item has been examined, the priority tag for the other has decayed with time (Yantis \& Jones, 1991). Alternatively, subjects may only be able to attend to or tag either onsets or offsets but not both, perhaps because they can program their attentional set for either onsets or offsets but not both, or perhaps because onset and offset stimuli compete for selection, with only one being selected in parallel.

In summary, when subjects are set to search for both an onset and an offset element simultaneously, at best only one of the two types of elements seems to take search priority and neither dominates the other. Again as in Experiment 1, subjects were set to search for both on- set and offset elements, since the target was always uniquely defined by one or the other. As speculated in Experiment 2, onsets may only dominate offsets when subjects are not specifically searching for both types of elements (i.e., when there is a neutral attentional set). Only when there is no rationale for selectively searching for both onsets and offsets may onsets dominate offsets. This was investigated in Experiment 4.

\section{EXPERIMENT 4 \\ Automatic Attention Capture by Onsets and Offsets in Multiple-Item Displays}

In this experiment, we aimed to determine whether onsets or offsets (or both) capture attention automatically when there is no rationale for subjects to selectively attend to those items (i.e., when the target location is not correlated with either onset or offset elements).

Subjects searched for the presence or absence of a letter $\mathrm{A}$ among $\mathrm{ns}$, Os, and figure $8 \mathrm{~s}$ formed by illuminating segments of a box figure 8 . On every trial, a single onset and offset stimulus both occurred. The target could be formed from the onset or the offset, or it could already be present in the display. By comparing search performance when the target was an onset, an offset, or a static element already present in the display it is possible to determine (1) whether onsets, offsets, or both capture attention automatically when there is no motivation for subjects to attend to them and (2) whether onsets dominate offsets for attention when there is control over overall luminance change and appearance of new objects or number of onsets versus offsets.

As in Experiment 4, several patterns of results were possible: (1) Onsets might capture attention automatically, but not offsets. In this case, onset trials would be more efficient than offset and static trials. (2) Onsets and offsets might both attract attention but onsets might dominate offsets, so that RTs to onset targets would be faster than those to offset targets but both would produce efficient search in comparison with static targets. (3) The reverse might happen; offsets might dominate onsets. (4) Either onsets or offsets could capture attention but the two stimuli would compete for selection. In the latter case, there should be search slopes that were half those in the static search condition, because, when the target was an onset or offset, it should, on the average, 
capture attention automatically on half the trials (see Experiment 3).

\section{Method}

Subjects. Twelve subjects ( 6 male and 6 female) between 18 and 26 years of age (mean, 20.8) were paid to participate in this study. All were students at the University of Birmingham and had self-reported normal or corrected-to-normal vision.

Stimuli. The stimuli consisted of a white A target with white $n$, figure 8 , and $O$ distractors. The stimuli were formed by illuminating segments of a box figure 8 and fell randomly within an $80-\mathrm{mm}$ high $\times 60$-mm-wide display area. The individual stimuli were $7 \mathrm{~mm}$ high $\times 4 \mathrm{~mm}$ wide. The display size was 6 or 12 items, and the target was present on $50 \%$ of the trials. All stimuli were generated and presented by an IBM-PC-compatible computer driving a standard VGA graphics card attached to a super VGA monitor. The viewing distance was approximately $70 \mathrm{~cm}$. Within one block of trials, four types of trial were possible at each display size: target absent trials, onset target present trials, offset target present trials, and static target present trials. On absent trials, equal numbers of $n$, figure 8 , and $O$ distractors were displayed, and after $100 \mathrm{msec}$, a figure 8 distractor changed into an $\mathrm{O}$ through the removal of one line segment while at the same time an $O$ distractor changed into a figure 8 by gaining one segment. On onset present trials, again equal numbers of the three types of distractors were displayed, but after $100 \mathrm{msec}$, an $\mathrm{n}$ distractor turned into an A by gaining a segment (to form an onset target) and an $O$ changed to an $n$ by losing a segment (offset distractor). On offset present trials, a figure 8 lost one segment to form an offset A target and an O gained one segment to form an onset figure 8 distractor. On static present trials, the A target was present from the outset (it always took the place of an $\mathrm{n}$ distractor), and after $100 \mathrm{msec}$, a figure 8 turned into an $\mathrm{O}$ and an $\mathrm{O}$ into a figure 8. RTs were measured from the onset of the initial search display (for static present trials) or from the formation of the onset or offset target on onset and offset present trials. Following Yantis and Jonides (1984), the probability of a target's being formed from an onset or offset element was equal to $1 / n$, where $n$ was the display size of the trial (see Table 4 for a breakdown of the number of each type of trial within a single block). This meant that there was no incentive for subjects to try to attend to either onset or offset stimuli, since the target was equally likely to be any of the other elements in the display.

Procedure. All subjects performed six blocks of 96 trials with a short rest between blocks in a single session lasting approximately $45-50 \mathrm{~min}$. Within each block were equal numbers of present and absent trials at each display size, and trial order was random within a block. Following a central 1,000 -msec fixation cross, the stimuli were displayed, and $100 \mathrm{msec}$ after that, an onset and offset occurred simultaneously; this display remained until the subjects responded. The subjects indicated the presence or absence of the target item by pressing either " $\mathrm{z}$ " or " $\mathrm{m}$ " on a standard computer keyboard. Response keys were counterbalanced across subjects. Immediate error feedback was given by the presentation of a $500-\mathrm{Hz}$ tone for $500 \mathrm{msec}$ on incorrect trials. There was then a 500 -msec blank screen, after which the next trial began.

\section{Results}

The six blocks of trials for each subject were combined, and the means for each condition were calculated by using RTs on correct trials only. Figure 4 and Table 5 show the mean correct RTs for each type of trial at each of the display sizes. Table 5 additionally shows the mean percentage error rates.

The results were initially analyzed in a two-way within-subjects ANOVA with the main factors of trial type
Table 4

Experiment 4: Number of Each Type of Trial Within a Single Block

\begin{tabular}{ccccccccc}
\hline & \multicolumn{3}{c}{ Display Size 6 } & & \multicolumn{3}{c}{ Display Size 12 } \\
\cline { 3 - 5 } \cline { 6 - 8 } Absent & \multicolumn{3}{c}{ Present } & & \multicolumn{3}{c}{ Present } \\
\cline { 2 - 8 } & Onset & Offset & Static & Absent & Onset & Offset & Static \\
\hline 24 & 4 & 4 & 16 & 24 & 2 & 2 & 20 \\
\hline
\end{tabular}

(absent, onset, offset, or static) and display size. This revealed significant main effects of trial type $[F(3,33)=$ $\left.22.35, M S_{\mathrm{e}}=42,022, p<.001\right]$ and display size $[F(1,11)=$ $\left.43.59, M S_{\mathrm{e}}=41,497, p<.001\right]$ and a significant trial type $\times$ display size interaction $\left[F(3,33)=27.61, M S_{\mathrm{e}}=\right.$ $4,746, p<.001]$. As can be seen in Figure 4, RTs were faster for present trials than for absent trials, and they increased with display size, with absent trials showing a larger display size effect than did present trials.

Of most interest was whether there was a difference between the three types of present trials, and in particular whether onset or offset trials would show a smaller display size effect than would static trials. This was assessed by performing a further two-way ANOVA on the present trial data only. This again revealed significant main effects of trial type $\left[F(2,22)=4.59, M S_{\mathrm{e}}=5,661\right.$, $p<.05]$ and display size $\left[F(1,11)=33.39, M S_{\mathrm{e}}=\right.$ $22,372, p<.001]$ and a significant trial type $\times$ display size interaction $\left[F(2,22)=5.49, M S_{\mathrm{e}}=2,916, p<.05\right]$. On static target trials, RTs were slower and they increased more with display size than on onset or offset target

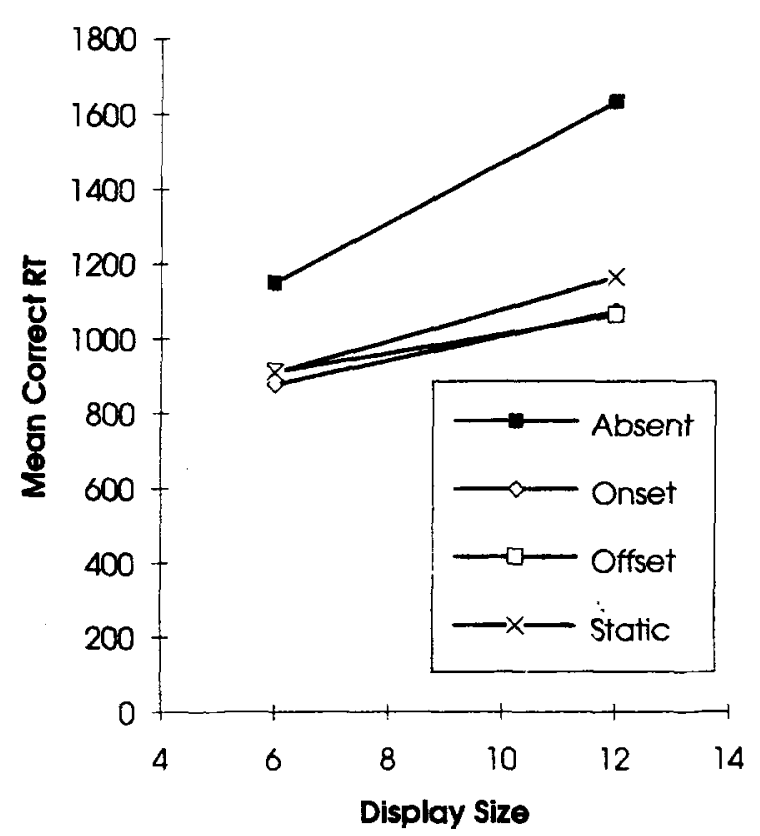

Figure 4. Mean correct reaction time to indicate the presence/absence of a box letter $A$ target unreliably formed from an onset or offset or neither among block figure ns, $O s$, and $8 \mathrm{~s}$ as a function of display size. 
Table 5

Experiment 4: Reaction Times and Percent Error Rate for Automatic Attention Capture by an A Target Among $\mathrm{n}, O$, and Figure 8 Distractors as a Function of Presentation (Static, Onset, Offset)

\begin{tabular}{lccccc}
\hline & \multicolumn{4}{c}{ Display Size } \\
\cline { 2 - 5 } \multicolumn{1}{c}{ Trial Type } & \multicolumn{3}{c}{6} & & 12 \\
\cline { 2 - 5 } & $\mathrm{RT}$ & $\% \mathrm{E}$ & $\mathrm{RT}$ & $\% \mathrm{E}$ \\
\hline Absent & $1,148.0$ & 1.1 & $1,635.0$ & 1.0 \\
Present onset & 875.5 & 4.2 & $1,074.1$ & 8.3 \\
Present offset & 909.6 & 4.5 & $1,064.4$ & 9.8 \\
Present static & 908.0 & 5.0 & $1,165.8$ & 7.3 \\
\hline
\end{tabular}

trials. However, although RTs were faster overall for onset and offset targets, the error rates on those trials were also higher by about $1.5 \%-2.5 \%$, suggesting a possible speed-accuracy tradeoff.

Finally, in a further two-way ANOVA, onset and offset present trials were compared directly. This revealed a significant effect of display size $[F(1,11)=19.61$, $\left.M S_{\mathrm{e}}=19,110, p<.001\right]$, but neither trial type $[F(1,11)=$ $0.32, M S_{\mathrm{e}}=5,520, p=.5811$ nor the trial type $\times$ display size interaction reached significance $[F(1,11)=$ $\left.2.40, M S_{\mathrm{e}}=2,396, p=.150\right]$. This indicates that onset targets did not capture attention any more efficiently than offset targets.

\section{Discussion}

This experiment was intended to determine whether onsets that did not form new objects or offsets would capture attention automatically even when there was no advantage for subjects to attend selectively to those items. We also measured whether contour onsets or offsets would have an equal power for attention capture. ${ }^{2}$

When a target was a static stimulus, the search rate was $43 \mathrm{msec}$ and $81 \mathrm{msec} /$ item on present and absent trials. This pattern is consistent with a relatively difficult serial search. However, when the target was formed from either an onset or an offset element, search was more efficient ( $33 \mathrm{msec} / \mathrm{item}$ for the onset target and $26 \mathrm{msec} /$ item for an offset target). This suggests that even in the absence of any rationale for attending to onset or offset stimuli, these stimuli were assigned higher priority for search than were other (static) stimuli. However, there are several reasons for arguing that the contour onsets and offsets did not reliably capture attention automatically. For instance, although the search slopes for onset and offset targets were smaller than those for static targets, there was still a robust display size effect. Also, the faster RTs overall for onset and offset targets may to some degree have been due to subjects trading speed for accuracy in those conditions. Thus we cannot conclude that contour onsets and offsets reliably captured attention. This could have been because (1) contour onsets and offsets are only weakly tagged for priority allowing only one (or sometimes neither) to be examined by the time that priority tags have decayed or (2) the onset and offset stimuli compete and only the winner is assigned attentional priority. This would lead to improved detection when the target was an onset or offset on only $50 \%$ of the trials (again there were insufficient trials to allow a formal analysis of this proposal). In Experiment 5, we tested these hypotheses by repeating Experiment 4 but by having only one contour onset or one offset occur in the display rather than both simultaneously. Now there could be no competition between onset and offset elements since only one was present, and so the onset or offset should always capture attention and produce flat search functions. On the other hand, if contour onsets and offsets were only tagged weakly, we would again expect nonflat search functions, since the weakness of the tagging might not always be sufficient to ensure attention capture.

\section{EXPERIMENT 5 \\ Automatic Attention Capture by Individual Contour Onset and Offset Stimuli}

\section{Method}

Subjects. Eight subjects ( 3 male and 5 female) between 19 and 36 years of age (mean, 22.1) were paid to participate. All were students at the University of Birmingham and had self-reported normal or corrected-to-normal vision.

Stimuli. The stimulus displays and equipment were essentially the same as those in Experiment 4, except that rather than there being one onset and one offset presented simultaneously in the display there was only either one onset or one offset (but not both). Thus, on absent trials, $100 \mathrm{msec}$ after the distractors were presented, either a single $O$ distractor changed to a figure 8 distractor or with equal probability a figure 8 distractor changed into an $O$ distractor. On onset present trials, a single $n$ changed into an $A$, and on offset present trials, a figure 8 changed to an A. On static present trials, the A was again present from the outset, but after $100 \mathrm{msec}$, either a single $O$ changed to a figure 8 or with equal frequency, a figure 8 changed into a figure $O$. Again the probability of the target's being formed from the onset or offset stimulus was equal to $1 / n$, where $n$ was the display size. Thus there was no advantage for subjects to try to attend preferentially to either the onset or the offset stimuli.

Procedure. The procedure was the same as in Experiment 4, except that each subject now performed eight blocks of 96 trials with a short rest between blocks in a single session lasting $1 \mathrm{~h}$.

\section{Results}

The eight blocks of trials for each subject were combined, and the means for each condition were calculated by using RTs on correct trials only. Figure 5 and Table 6 show the mean correct RTs for each type of trial at each display size and the mean percent errors.

The results were analyzed in a two-way within-subjects ANOVA with the main factors of trial type (absent, onset, offset, or static) and display size. This revealed significant main effects of trial type $[F(3,21)=25.39$, $\left.M S_{\mathrm{e}}=20,387, p<.001\right]$ and display size $[F(1,7)=$ $\left.42.53, M S_{\mathrm{e}}=19,691, p<.001\right]$ and a significant trial type $\times$ display size interaction $\left[F(3,21)=28.66, M S_{\mathrm{e}}=\right.$ $3,872, p<.001]$. As can be seen in Figure 5, RTs were faster on present trials than on absent trials, and they increased with display size, with absent trials showing a larger effect of display size than did present trials. 
As in the previous experiment, of most interest was the difference between the three types of present trials. A further two-way ANOVA was performed on the present trial data only. This again revealed significant main effects of trial type $\left[F(2,14)=6.47, M S_{\mathrm{e}}=7,564, p<.01\right]$ and display size $\left[F(1,7)=22.62, M S_{\mathrm{e}}=11,929, p<.001\right]$ and a significant trial type $\times$ display size interaction $[F(2,14)=$ $\left.9.27, M S_{\mathrm{e}}=1,872, p<.005\right]$. RTs when the target was a static item were slower and increased more with display size than when the target was formed by an onset or an offset. A final two-way ANOVA was used to compare onset and offset trials. This revealed a significant main effect of display size $\left[F(1,7)=10.75, M S_{\mathrm{e}}=9,505, p<.05\right]$ but neither the main effect of trial type $\left[F(1,7)=0.03, M S_{\mathrm{e}}=\right.$ $11,184, p=.877]$ nor the trial type $\times$ display size interaction $\left[F(1,7)=0.68, M S_{\mathrm{e}}=2,809, p=.435\right]$ reached significance. The search slope on absent trials was $77.5 \mathrm{msec} /$ item; on static trials, $37.3 \mathrm{msec} / \mathrm{item}$; on onset trials, $16.3 \mathrm{msec} / \mathrm{item}$; and on offset trials, $21.4 \mathrm{msec} / \mathrm{item}$.

\section{Discussion}

In this experiment, only a single onset or offset was ever presented (but not both simultaneously), and this change was not correlated with the target position. Again, search was more efficient when the target was formed from an onset or an offset as opposed to a static item. However, as in Experiments 3 and 4, we also obtained nonflat search functions for onset and offset targets despite the lack of a competing luminance change in the display. This suggests that even in isolation, contour onsets and offsets do not capture attention automatically in comparison with the new-object onsets used in previous experiments (e.g., Yantis \& Hillstrom, 1994;

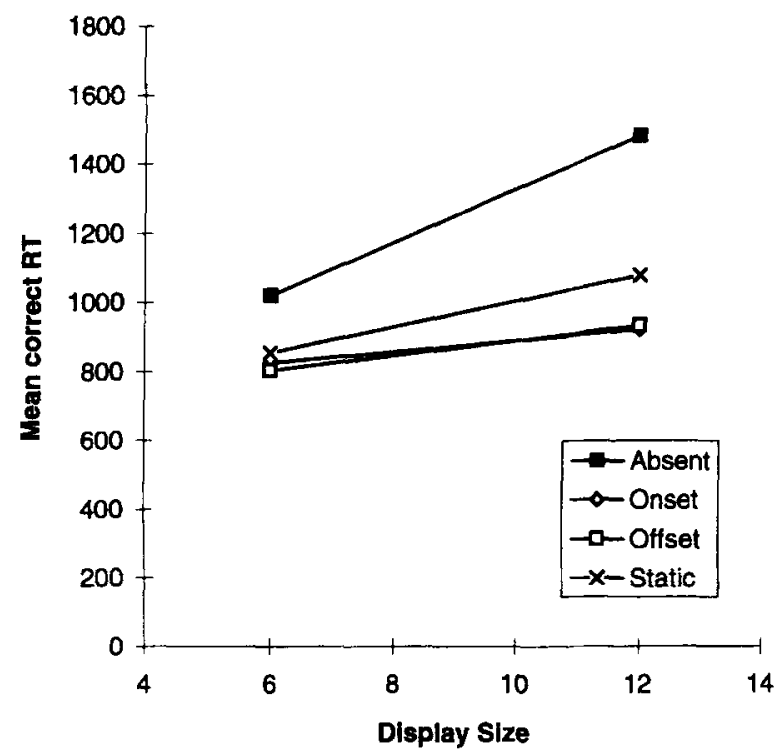

Figure 5. Mean correct reaction time to indicate the presence/absence of a box letter $A$ target unreliably formed from a single onset or offset or neither among block figure $\mathrm{ns}, \mathrm{Os}$, and $8 \mathrm{~s}$ as a function of display size (only one single onset or offset is presented in the display).
Table 6

Experiment 5: Reaction Times and Percent Error Rates for Automatic Attention Capture by an A Target Among n, $\mathbf{O}$, and Figure 8 Distractors as a Function of Presentation (Static, Onset, Offset) When Only a Single Onset or a Single Offset Occurred in a Display

\begin{tabular}{lrrrrr} 
& \multicolumn{4}{c}{ Display Size } \\
\cline { 2 - 4 } \multicolumn{1}{c}{ Trial Type } & \multicolumn{2}{c}{6} & & \multicolumn{2}{c}{12} \\
\cline { 2 - 5 } & RT & \% E & & RT & $\%$ E \\
\hline Absent & $1,019.4$ & 1.2 & $1,484.6$ & 1.5 \\
Present onset & 826.1 & 2.4 & 923.6 & 7.9 \\
Present offset & 804.6 & 7.1 & 933.1 & 7.9 \\
Present static & 855.6 & 3.5 & $1,079.5$ & 7.3 \\
\hline
\end{tabular}

Yantis \& Jonides, 1984). This suggests that the lack of automatic attention capture for the contour onsets and offsets in Experiments 3 and 4 was not due to the onset and offset competing with each other for attention but rather due to their being tagged only weakly for attention. This might result in either one alone being examined, with random selection of target type, or neither being examined with priority on a given trial.

\section{GENERAL DISCUSSION}

In Experiment 1, we showed that when subjects are "set" to search for single contour onset or offset targets, their detection is rapid and parallel across the visual field. Moreover, detection of contour onset stimuli and detection of contour offset stimuli were equally efficient. Thus there is no difference in the efficiency with which single contour onset or offset elements can be detected during guided search.

In Experiment 2, we looked at the ability of onsets and offsets presented simultaneously to capture attention automatically. This showed that when the target was equally likely to be an onset or offset element and when factors such as overall luminance change, the number of onsets and offsets occurring in a single display, and the creation of new objects was controlled for, onsets did not dominate offsets. The display size effect that we found for onset targets in Experiment 2 concurs with other recent data indicating that targets defined by contour onsets do not capture attention irrespectively of other stimuli in visual displays.

In Experiments 3 and 4, onsets and offsets were presented simultaneously and so were potential competitors. In Experiment 3, subjects were set to detect a target that could be either the onset or the offset element and hence examined "guided" search. In Experiment 4, the onset and offset were uncorrelated with the target location. In both experiments, onset or offset targets were detected faster than targets in a baseline conjunction condition, indicating that they gained a higher priority for search than static items. Nevertheless, display size effects were apparent, with the slopes on trials with onset and offset targets about half those on trials with static targets. This suggested that in both guided search 
and nonguided search conditions, contour onsets and offsets might directly compete for attentional resources with one item winning at the expense of the other. However, Experiment 5 showed that even when contour onsets and offsets were presented individually, there remained robust display size effects. The data are consistent with contour onsets and offsets being tagged only weakly for automatic attentional priority. Under guided search conditions, the weak tagging of the stimuli may allow time for only one item to be examined before the remaining priority tags decay to background levels, hence producing flat search slopes in Experiment $l$ but not in Experiment 3 .

These results are somewhat different from those recently presented by Yantis and Hillstrom (1994) showing that a luminance change is neither sufficient nor necessary for automatic attention capture. In one experiment, they presented subjects with box figure 8 premasks, which then changed to letter stimuli, and as the premasks changed, one of them was briefly brightened (the brightened premask was unrelated to the target position). Subjects then indicated which of two possible targets was in the search display. Although there was a trend for the effect of display size to be smaller on trials when the target was formed from the brightened premask rather than one of the nonbrightened ones, this was not statistically significant. They explained the lack of attention capture by the brightened stimulus by suggesting that since the attentional set of the subjects did not include luminance increments (because in their task luminance changes were unrelated to the target position), such stimuli would not capture attention automatically. It follows that onset stimuli captured attention in previous studies because such stimuli were new objects, not because they produced an increase in luminance.

However, we found that targets defined by contour onsets and offsets were assigned a higher priority than static targets, even though onset and offset targets did not reliably capture attention on all trials. In our experiments, the onsets and offsets did not create new objects, but they did change the identity of the objects by adding or deleting contours. In Yantis and Hillstrom (1994), brightening did not change the identity of the targets. Yantis and Hillstrom argued that new objects captured attention because they required a new "object file" (see Kahneman, Treisman, \& Gibbs, 1992) to be created, whereas old objects simply required the updating of an already existing object file. However, it is possible that "new objects" are simply tagged more strongly for attentional priority than changed objects. So attention tends to be drawn to new objects-but in the absence of new objects, attention is drawn to "changed objects," and the amount of change may then dictate which takes priority. This makes sense ecologically, since a new object appearing from nowhere would require adding to an internal model of the environment and could be far more threatening than a previously detected object that had simply changed some of its attributes. Future work could investigate this claim by measuring the effect of secondary tasks on the ability of new-object onsets in comparison with contour onsets to capture attention automatically. If contour onsets are only tagged weakly, a secondary task should disrupt attention capture by targets defined by contour onsets more than those defined by new-object onsets. Also the amount of change may be directly related to the strength of tagging. However, note that it may be that a changed object can never be tagged more strongly than the appearance of a new object.

The present evidence for weak attentional tagging resembles findings reported recently by Todd and Kramer (1994). They measured the power of irrelevant singletons defined by color or luminance to capture attention automatically in a visual search task for a target defined by shape. They found that when the target was the singleton item, it was detected more efficiently than when it was not distinguished by the irrelevant color or luminance attribute as well as shape, but such singleton targets did not produce flat search slopes (cf. Jonides \& Yantis, 1988). There appears to be a continuum of attentional tagging, ranging from "automatic" capture of attention by new objects, to weak prioritization of attention by contour onsets and offsets (and perhaps by stimuli defined by unique values on dimensions such as color; see Todd \& Kramer, 1994). Such a continuum would fit with approaches to visual selection such as those proposed by Bundesen (1990) and Duncan and Humphreys (1989). These authors suggest that selection efficiency is determined by the amount of attentional weight drawn to stimuli, with attentional weighting varying continuously according to the characteristics of the stimuli and the "selection schedule" or attentional set of the observer.

Our data also agree with other recent evidence indicating that abrupt onsets do not capture attention in a fully automatic way; for instance, invalid onsets do not necessarily disrupt performance in tasks in which stimuli occur with high validity at other locations (Yantis \& Jonides, 1990; see also Theeuwes, 1991) and in which other dimensions are deemed important for task performance (Folk et al., 1992). Our data extend these prior results, suggesting that strong attentional weighting to onset stimuli is not even a "default" setting for the attentional system (cf. Folk et al., 1992), since we found no evidence for onset over offset dominance when the stimuli were matched on previously uncontrolled factors. However, visual luminance change (increment or decrement) may be a default attentional setting, since we found evidence for, albeit weak, attentional prioritization by both onsets and offsets even when the target position was unrelated to the luminance changes (Experiments 4 and 5).

In summary, we have shown that contour onsets (onsets that do not form new objects) do not take search priority over contour offsets either in goal-directed visual search or under stimulus-driven attention conditions. Moreover, our findings suggest that contour onsets and offsets may have only a weak power to attract attention automatically. This compares with previous results 
which have shown that onsets that form new objects dominate offsets for attentional capture (e.g., Yantis \& Hillstrom, 1994; Yantis \& Jonides, 1984). These differences may be due to a new object's requiring the creation of a new-object file (Yantis \& Hillstrom, 1994), whereas a changed object requires only the updating of an already existing file; hence a changed object will draw less attentional weight to itself in visual selection. Our results support the claim that, in previous studies, rapid visual onsets may well have been "special" by virtue of their coinciding with the creation of new objects, but luminance increments per se are no more special than luminance decrements.

\section{REFERENCES}

Bundesen, C. (1990). A theory of visual attention. Psychological Review, 97, 523-547.

DunCan, J., \& Humphreys, G. W. (1989). Visual search and stimulus similarity. Psychological Review, 96, 433-458.

Folk, C. L., \& ANNETT, S. (1994). Do locally defined feature discontinuities capture attention? Perception \& Psychophysics, 56, 277-287.

Folk, C. L., Remington, R. W., \& Johnston, J. C. (1992). Involuntary covert orienting is contingent on attentional control settings. Journal of Experimental Psychology: Human Perception \& Performance, 18, 1030-1044.

Folk, C. L., Remington, R. W., \& Johnston, J. C. (1993).Contingent attentional capture: A reply to Yantis (1993). Journal of Experimental Psychology: Human Perception \& Performance, 19, 682-685.

HiLlstrom, A. P., \& YANTIS, S. (1994). Visual motion and attentional capture. Perception \& Psychophysics, 55, 399-411.

HumphreYs, G. W., QuinLan, P. T., \& RiDDOCH, M. J. (1989). Grouping processes in visual search: Effects of single- and combinedfeature targets. Journal of Experimental Psychology: Human Perception \& Performance, 118, 258-279.

JONIDES, J., \& YANTIS, S. (1988). Uniqueness of abrupt visual onset in capturing attention. Perception \& Psychophysics, 43, 346-354.

Kahneman, D., Treisman, A., \& GibBs, B. J. (1992). The reviewing of object files: Object-specific integration of information. Cognitive Psychology, 24, 175-219.

MILLER, J. (1989). The control of attention by abrupt visual onsets and offsets. Perception \& Psychophysics, 45, 567-571.

Quinlan, P. T., \& HuMphreYs, G. W. (1987). Visual search for targets defined by combinations of color, form, shape, and size: An examination of the task constraints on feature and conjunction searches. Perception \& Psychophysics, 41, 455-472.

THEEUWES, J. (1991). Exogenous and endogenous control of attention: The effect of visual onsets and offsets. Perception \& Psychophysics, 49, 83-90.
TodD, S., \& Kramer, A. F. (1994). Attentional misguidance in visual search. Perception \& Psychophysics, 56, 198-210.

Treisman, A., \& GeladE, G. (1980). A feature-integration theory of attention. Cognitive Psychology, 12, 97-136.

YANTIS, S. (1993). Stimulus-driven attentional capture and attentional control settings. Journal of Experimental Psychology: Human Perception \& Performance, 19, 676-681.

YANTIS, S., \& HiLlSTROM, A. P. (1994). Stimulus-driven attentional capture: Evidence from equiluminant visual objects. Journal of Experimental Psychology: Human Perception \& Performance, 20, 95-107.

YANTIS, S., \& JoHNSON, D. N. (1990). Mechanisms of attentional priority. Journal of Experimental Psychology: Human Perception \& Performance, 16, 812-825.

YANTIS, S., \& JoNES, E. (1991). Mechanisms of attentional selection: Temporally modulated priority tags. Perception \& Psychophysics, 50, 166-178.

YANTIS, S., \& JONIDES, J. (1984). Abrupt visual onsets and selective attention: Evidence from visual search. Journal of Experimental Psychology: Human Perception \& Performance, 10, 601-621.

YANTIS, S., \& JONIDES, J. (1990). Abrupt visual onsets and selective attention: Voluntary versus automatic allocation. Journal of Experimental Psychology: Human Perception \& Performance, 16, 121-134.

YANTIS, S., Meyer, D. E., \& SMiTh, J. E. K. (1991). Analyses of muitinomial mixture distributions: New tests for stochastic models of cognition and action. Psychological Bulletin, 110, 350-374.

\section{NOTES}

1. Note that the contour offsets in the present paper were essentially the same as the offsets used in previous studies, but we will call them contour offsets for the sake of consistency across the conditions.

2. As pointed out by a reviewer, in both Experiments 3 and 4, $100 \mathrm{msec}$ before the contour onset or offset, there were lots of onsets and no offsets as a result of the initial display items being presented. If the visual system shows short-term habituation to onsets, then these initial onsets may have reduced the sensitivity to onsets, thus favoring the detection of offset stimuli. However, we feel that this is unlikely because, first, in Experiment 2, there was a gap of 1,000 msec (rather than $100 \mathrm{msec}$ ) between the initial display onset and the onset and offset stimuli and yet there was still no advantage for the onset stimulus. This was true even at Display Size 2 when only a single onset and offset were present. Second, the initial onsets may have tended to make subjects "set" themselves for onsets over offsets. Subjects first had to fixate an "onset fixation cross" and were then presented with items, all of which were onsets and any of which could be the target. Thus the relative importance of onsets in the experiments may have caused subjects to adopt an attentional set for onset stimuli. This would work against a possible advantage for offset stimuli (see also Folk et al., 1992,1993 , for a similar argument about onsets in such experiments and the "inducement" of attentional sets).

(Manuscript received November 1, 1993; revision accepted for publication December 12, 1994.) 